\title{
MICETOMA PODAL POR FUSARIUM SOLANI (Mart.) Appel \& Wollenweber
}

\author{
Alicia G. Luque, María T. Mujica, \\ María L.D'Anna y Delia P.Alvarez. \\ Centro de Referencia de Micología de Rosario (CEREMIC \\ Facultad de Ciencias Bioquímicas y Farmaceuticas. Universidad \\ Nacional de Rosario. Suipacha 531. (2000) Rosario. Santa Fé. \\ República Argentina.
}

Palabras clave: Micetoma - Fusarium solani - gránulos eumicóticos.

Key word :Mycetoma - Fusarium solani - eumicotic grains.

\section{RESUMEN}

Se presenta un caso de micetoma de pie derecho, producido por Fusarium solani, en un hombre de 24 años procedente del Chaco. La infección se produjo debido a una lesión con una astilla de quebracho.

La determinación del agente causal fue realizada en muestras seriadas (biopsias y secreciones) por el estudio de los gránulos, exdmenes directos, coloraciones y caracteres culturales en medio de Agar Sabouraud-glucosa, Agar Sabouraud cloranfenicol, Agar extracto de Malta y Cerebro Corazón.

Se considera a Fusarium solaniy otras especies del género, como raros agentes productores de micetoma, pero las cepas con capacidad de crecer a elevadas temperaturas y las circunstancias apropiadas en el hospedador, permiten su adaptación al ambiente tisular y el inicio de esta micosis.

\section{INTRODUCCION}

El micetoma es un sindrome clínico caracterizado por tumoración de la región afectada, fistulación y presencia de gránulos.

\section{SUMMARY}

[Podal Mycetoma by Fusarium solani.]

Onecase of mycetoma on the right foot caused by Fusaqrium solani in a 24 years-old man from Chaco (Angentina) is exposed.

The focal infection was produced after an injury with a quebracho splinter.

The determination of the etiological agent was done in consecutive samples (biopses and secretions) thouh studying the granules, direct exams, colorations and culture characters in Sabourcud Glucosa Agar, Sabouraud Glucosa Cloranphenicol Agar, Malt Extract Agar and Brain Heart Agar.

Fusarium solani and other species of the same genus were considered as unusual mycetoma producers but it has been observed that soil strains with capacity of growing at high temperature and in appropiate circunstances in the host are capable of adapting and producing this micosis.

Las lesiones son localizadas y se encuentran frecuentemente en manos y pies; son indoloras, deformantes. comprometiendo los tejidos cutáneos, subcutáneos y osteoarticulares (8).

Los agentes etiológicos pueden ser bacterias 
del orden de los Actinomycetales (Micetomas actinomicóticos)y hongos (Micetomas maduromicóticos o eumicóticos) (9).

Dentro de los áltimos los más comunmente aislados son: Pseudoallescheria boydii, Madurella grisea y Madurella micetomatys; con una menor prevalencia, Acremonium kiliense, Leptosphaeria, senegalensis, Pyrenochaeta romeroi y entre los excepcionales se encuentran especies de, Aspergillus, Fusarium y otros hongos del suelo (8).

El género Fusarium puede dar infecciones cutáneas y profundas. Dentro de las primeras se lo ha recuperado de un granuloma facial (1) y úlceras; de onicomicosis (4) (7) y queratinomicosis (10). Las infecciones subcutáneas y profundas son menos frecuentes que las cutáneas y se producen en pacientes con graves deficiencias inmunológicas(8).

Casos esporádicos de Fusarium como agente productor de micetoma fueron encontrados en Asia, Africa (3) e Italia (5).

El objetivo de este trabajo es comunicar el hallazgo de F. solani como productor de un micetoma podal.

\section{Caso clínico:}

Paciente de 24 años de sexo masculino que fue enviado a este Centro para la identificación micológica del agente causal de una lesión en el miembro inferior derecho.

Antecedentes personales: nació y vivió en la provincia del Chaco hasta los 19 años, luego se trasladó a Rosario, donde habita en la actualidad desempeñándose como transportista de leños.

Tres meses atrás sufre una pinchadura con una astilla de quebracho en el sitio afectado. La lesión se localiza en la región lateral externa del pie derecho ocasionándole dificultad en la marcha. Se presenta como una zona hiperpigmentada, de aspecto tumoral, dolorosa a la palpación y con dos trayectos fistulosos abiertos.

El estudio anátomopatológico describe un tejido fibroso, denso, de aspecto cicatrizal, con múltiples focos rellativamente bien delimitados e inclusiones purulentas inespecíficas, no existiendo reacción de células epiteliodes o gigantes. Mostraba algunos focos purulentos que poseían en su interior extensos acúmulos de gérmenes y filamentos fúngicos. Este cuadro clínico presentaba el aspecto clínico de un micetoma eumicótico.

\section{Estudio micológico:}

Se realizaron tres tomas de muestras. El primer material fue la secreción de una de las fístulas, el segundo biopsias del tejido cutáneo y subcutáneo tomado de las paredes internas laterales y techo de la cavidad del trayecto fistuloso y en tercer término se obtuvo una secreción de drenaje sero-sanguinolenta.

Los exámenes directos se realizaron con $\mathrm{KOH}$ al $20 \%$ y con colorante Gueguén. Se efectuaron tinciones con May Grunwald Giemsa, Ziehl Neelsen y Gram-Nicholle, sembrándose los materiales en los medios de Agar Sabouraud-glucosa, Agar Sabouraud Cloranfenicol, Agar Extracto de Malta y Agar Cerebro-Corazón, e incubándose a $28^{\circ}$ y $37^{\circ} \mathrm{C}$ por 15 días.

Las dos primeras muestras procesadas no mostraron elementos fúngicos a la inspección microscópica, ni desarrollo en los cultivos.

En la última muestra se observaron gránulos blancos, blandos, de aproximadamente $1 \mathrm{~mm}$ que microscópicamente revelaron filamentos fúngicos. En los cultivos se obtuvo en todos los medios empleados un desarrollo de aspecto afelpado, blanquecino, que al observarlo en preparaciones directas mostró filamentos tabicados, macro y microconidios, lo cual permitió su ubicación taxonómica en el género Fusarium.

Basándonos en la clave taxonómica de Booth, (2) realizamos los estudios morfológicos correspondientes de la cepa, los cuales permitieron su determinación biológica como Fusarium solani (Mart.) Appel \& Wollenweber.

\section{DISCUSION}

Cepas de Fusarium solani, F. oxysporum y F. moniliforme, fueron encontradas en forma excepcional como productoras de un micetoma. Muchos hongos y actinomicetos,sobre todo las cepas capaces de crecer a temperaturas elevadas y en condiciones apropiadas pueden adaptarse al ambiente tisular y provocar un micetoma. En el presente caso, un trauma producido con material contaminado, una falta de asepsia y factores del huésped posibilitaron la adaptación de F. solani, lo cual produjo el cuadro clínico. 
Existen dificultades en el diagnóstico micológico de esta micosis (6): la escasa secreción que producen estos procesos, las biopsias tomadas de lugares no apropiados, la contaminación bacteriana de los gránulos que se encuentran en las partes más externas de las fístulas y por último la falta de viabilidad de los agentes etiológicos.

En este caso clínico fue necesario el procesamiento de muestras seriadas: biopsias obtenidas de distintos trayectos fistulosos y secreciones, lográndose el aislamiento y visualización de los gránulos del agente causal en sólo una de ellas.

Al observar los gránulos producidos por este hongo pudimos observar en la parte periférica, hifas vesiculosas no organizadas con una reacción inflamatoria inespecífica, sin reacción de células gigantes ni epitelioides. A diferencia del patrón histopatológico mostrado por otros hongos capaces de producir gránulos característicos, no se presentó la reacción hística común en los hongos aislados de micetomas eumicóti$\cos$.

\section{REFERENCIAS}

1. Benjamin, R.P; Callaway, J.L. \& Conant, N.I. (1970). Facial granuloma associated with Fusarium infection.Archives of Dermatology 101 : 598-600.

2. Booth, C. (1977). Fusarium laboratory guide to the identification of the major species. C.M.I. England.

3. Destumbes, P. (1978). Histological Diagnostic of Mycetomas granules. Presentado en el Simposio Internacional de Micetomas. Barquisimeto. Venezuela.

4. Luque, A.G.; Ramos, L.L. \& Amigot, S.L (1989). Onicomicosis producida por Fusarium solani. Rev. Arg. Micologia $81: 22-24$

5. Morganti, L. (1978). Micetomas en Europa. Presentado en el Simposio Internacional de Micetomas. Barquisimeto, Venezuela.
6. Negroni, R; Astarloa, L.; Lascano González, J. (1979). Micetoma podal por Streptomyces somaliensis. Presentación del primer caso argentin0o. Rev. Arg. Micología $2: 20-25$.

7. Piontelli, E.; Toro, MA. (1987). Comentarios biomorfológicos y clínicos sobre el género Fusarium. Hialohifomicois en uñas. Boletín Micológico. Chile; 3 : 213-221.

8. Rippon, J.W. (1990). Micología Médica. Hongos y actininomicetos patógenos. Interamericana Mc Graw Hill México.

9. Torres-Rodrfguez, J. M. (1987). Micosis que afectan piel y mucosas. Ediciones Royma Barcelona.

10. Zapater, R. C. (1983). Consideraciones sobre las micosis oculares. Rev. Arg. Micología 6 : 31-32. 